\title{
OPTIMASI E-COMMERCE DENGAN PENERAPAN TEKNIK SEO (SEARCH ENGINE OPTIMIZATION) UNTUK MENINGKATKAN PENJUALAN PADA UKM NIDA SASIRANGAN
}

\author{
Adi Pratomo ${ }^{1}$, Effan Najwaini ${ }^{2}$, Agus irawan ${ }^{3}$, Mey Risa $^{4}$ \\ Politeknik Negeri Banjarmasin ${ }^{1,2,3,4}$ \\ adipratomo ${ }^{@}$ poliban.ac.id ${ }^{I}$ \\ effan ${ }^{\circledR}$ poliban.ac.id ${ }^{2}$
}

\begin{abstract}
Nida Sasirangan is a large sasirangan craftsman in Banjarmasin. Nida Sasirangan's sales are still limited to local sales in Banjarmasin. Nida Sasirangan has used social media to promote their products through Instagram but still has not sold them online so that their market is limited to Banjarmasin. Nida Sasirangan also had a website but could not optimally increase their sales.In Nida Sasirangan there was a problem in increasing sales due to the absence of Nida Sasirangan on the first page of Google search, both website search and local search. Nida Sasirangan once had a website but was no longer active so search engine optimization could not be carried out on the website. Sales are also still done offline through stores not using the marketplace.From these problems, the activities carried out "Optimization of E-Commerce with the Application of SEO (Search Engine Optimization) Techniques to Increase Sales in SMEs Nida Sasirangan". This activity is done by remaking the Nida Sasirangan website and applying SEO techniques to have good search results. In addition, an optimization of the local search results of Nida Sasirangan stores was also carried out. For online sales, stores have been made on popular marketplace sites in Indonesia where the store link will be placed on the Nida Sasirangan website. With this activity, Nida Sasirangan's product sales are expected to increase and product buyers Nida Sasirangan not only from the city of Banjarmasin, but also from other cities in Indonesia, even from abroad.
\end{abstract}

Keywords: sasirangan, nida, seo, banjarmasin

\begin{abstract}
ABSTRAK
Nida Sasirangan merupakan pengrajin sasirangan yang cukup besar di Banjarmasin. Penjualan Nida Sasirangan masih terbatas pada penjualan lokal di Banjarmasin. Nida Sasirangan sudah memanfaatkan sarana sosial media untuk mempromosikan produkproduk mereka melalui Instagram tetapi masih belum melakukan penjualan secara online sehingga pasar mereka hanya terbatas di wilayah Banjarmasin. Nida Sasirangan juga pernah mempunyai website tetapi belum bisa optimal meningkatkan penjualan mereka. Pada Nida Sasirangan terdapat masalah dalam meningkatkan penjualan dikarenakan tidak adanya Nida sasirangan pada halaman pertama pencarian Google, baik itu pencarian website maupun pencarian lokal (local ranking). Nida Sasirangan pernah mempunyai website tetapi sudah tidak aktif lagi sehingga tidak bisa dilakukan optimasi search engine terhadap website tersebut. Penjualan juga masih dilakukan secara offline melalui toko tidak memanfaatkan marketplace. Dari permasalahan tersebut maka dilaksanakan kegiatan "Optimasi E-Commerce dengan Penerapan Teknik SEO (Search Engine Optimization) untuk Meningkatkan Penjualan pada UKM Nida Sasirangan". Kegiatan ini
\end{abstract}


dilakukan dengan membuat ulang website Nida Sasirangan dan menerapkan teknik SEO agar memiliki hasil pencarian yang baik. Selain itu juga dilakukan optimasi terhadap hasil pencarian lokal toko Nida Sasirangan. Untuk penjualan secara online telah dibuat toko pada situs marketplace popular di Indonesia dimana tautan tokonya akan diletakan di website Nida Sasirangan. Dengan kegiatan ini diharapkan penjualan produk Nida Sasirangan dapat meningkat dan pembeli produk Nida Sasirangan tidak hanya dari kota Banjarmasin, tetapi juga dari kota lain di Indonesia, bahkan dari luar negeri.

Kata Kunci: sasirangan, nida, seo, banjarmasin

\section{PENDAHULUAN}

\section{Analisis Situasi}

Sasirangan merupakan kain tradisional yang berasal dari Kalimantan Selatan yang telah ditetapkan oleh Kementerian Pendidikan dan Kebudayaan sebagai salah satu dari 33 kain tradisional warisan budaya tak benda di Indonesia. Sasirangan berasal dari kata sirang atau menyirang yang dalam bahasa banjar berarti menjelujur atau teknik menjahit menggunakan tangan (Kholis, 2016; Annisa, 2014). Sesuai dengan istilah namanya, motif kain sasirangan dibuat dengan menjahit terlebih dahulu kain dengan teknik jelujur. Benang jahitan kemudian ditarik hingga kain mengerut dan setelah itu diberi warna pada jahitan jelujurnya sehingga menghasilkan motif yang cantik (Abdi, 2011). Pada mulanya kain sasirangan hanya dibuat untuk mengobati orang sakit dan mengusir roh jahat, sehingga hanya orang tertentu yang dapat membuat kain ini, tetapi sekarang kain sasirangan dapat dibuat oleh siapa saja asalkan mempunyai keterampilan untuk membuatnya (Ganie, 2014; Seman, 2008). Saat ini di Kalimantan Selatan banyak sekali pengrajin yang mampu membuat kain sasirangan dengan berbagai motif yang menarik.

Pembuatan kain sasirangan umumnya masih dilakukan secara tradisional, mulai dari tahap mendesain motif, merajut, mencelup, membuka rajutan, mencuci dan menyetrika. Rumitnya pembuatan kain sasirangan dan keunikan motifnya membuat kain sasirangan bayak diminati baik itu warga asli suku banjar maupun para wisatawan. Banyaknya peminat sasirangan membuat industri sasirangan menjadi Komoditi/Produk/Jenis Usaha (KPJU) unggulan untuk sektor industri (Badan Pusat Statistik Provinsi Kalimantan Selatan, 2009).

Sebagai produksi unggulan, pemerintah Kalimantan Selatan bekerja sama dengan Bank Indonesia telah melakukan berbagai langkah untuk meningkatkan jumlah pengusaha atau pengrajin sasirangan. Usaha yang dilakukan antara lain dengan membentuk Rumah Sasirangan dimana setiap 3 hari dalam seminggu mengadakan pelatihan, membentuk kelompok usaha dan memberikan bantuan sarana produksi (Aida, 2015). Selain itu pemerintah juga membentuk kawasan khusus sasirangan yang diberi nama kampung sasirangan sebagai pusat penjualan sasirangan. Nida sasirangan merupakan salah satu UKM yang dulunya memasarkan produknya di kampung sasirangan.

Nida Sasirangan merupakan usaha milik Bapak Asbullah dan Ibu Hairatu yang telah berdiri lebih dari 20 tahun. Saat ini usaha Nida Sasirangan dijalankan oleh keluarga Bapak Asbullah beserta anak-anaknya. Nida Sasirangan dulunya 
memasarkan produknya di kampung sasirangan dengan menyewa tempat disana, tetapi dengan pertimbangan efisiensi usaha, Nida sasirangan hanya membuka toko di daerah Sungai Jingah Banjarmasin. Nida sasirangan merupakan pengrajin sasirangan yang tergolong besar, karena mampu memproduksi 30.000 meter kain sasirangan dalam satu tahun. Berdasarkan data Dinas Perindustrian dan Perdagangan Kota Banjarmasin Tahun 2014 hanya ada 3 pengrajin yang mampu memproduksi diatas 30.000 meter setahun. Untuk memproduksi kain sasirangan, Nida Sasirangan memberdayakan masyarakat sekitar untuk merajut (menjelujur), mencelup, membuka rajutan, mencuci dan menyetrika. Pemasaran yang dilakukan oleh Nida Sasirangan masih secara offline melalui toko mereka.

Nida Sasirangan sampai tahun 2015 melakukan pemasaran dengan cara manual, yaitu memanfaatkan promosi dari mulut ke mulut. Nida Sasirangan juga melakukan penjualan melalui pameran-pameran yang diselenggarakan baik itu oleh pemerintah maupun swasta. Nida Sasirangan melakukan promosi dengan menuliskan alamat toko pada kotak kain sasirangan yang dijual, sehingga ketika kain tersebut dijadikan hadiah atau oleh-oleh bagi orang lain, orang tersebut dapat melihat alamat toko dari kotaknya. Strategi ini dilakukan Nida Sasirangan karena lokasi toko mereka berada pada lokasi yang jarang dilewati baik itu oleh penduduk lokal Banjarmasin maupun wisatawan.

Mulai tahun 2015, Nida Sasirangan sudah memanfaatkan sarana sosial media untuk mempromosikan produk-produk mereka melalui Instagram tetapi masih belum melakukan penjualan secara online sehingga pasar mereka hanya terbatas di wilayah Banjarmasin. Nida Sasirangan juga pernah mempunyai website tetapi belum bisa optimal meningkatkan penjualan mereka.

\section{Permasalahan Mitra}

Kamal (2015) telah melakukan penelitian menganalisis stategi pengrajin Nida Sasirangan yang menyimpulkan bahwa Nida Sasirangan berada pada posisi agresif dan dalam kondisi tumbuh dan membangun. Penelitian tersebut memberi saran berupa strategi yang perlu diterapkan oleh Nida Sasirangan, yaitu: penetrasi pasar, pengembangan produk dan pengembangan pasar. Penetrasi pasar bisa dilakukan dengan meningkatkan promosi penjualan melalui jejaring sosial dan website serta rutin mengikuti pameran-pameran. Berdasarkan saran tersebut, Nida Sasirangan telah melakukan penetrasi pasar melalui sosial media Instagram dan membuat website hanya saja belum optimal. Belum optimalnya promosi melalui teknologi berbasis internet ini dapat dilihat dari hasil pencarian mesin pencari dengan kata kunci 'sasirangan' atau 'sasirangan banjarmasin'. Toko Nida Sasirangan tidak berada pada halaman pertama pencarian Google untuk kata kunci 'sasirangan' baik itu untuk pencarian tempat (local ranking) maupun pencarian website. Pada pencarian lokasi dengan kata kunci sasirangan, Nida Sasirangan berada pada urutan ke 17.

Pada tahun 2016, Nida Sasirangan telah dibuatkan website melalui penelitian Rozaq, dkk (2016). Rozaq, dkk (2016) telah membuat website E-Commerce untuk Nida Sasirangan dengan alamat domain www.nida-sasirangan.co.id dan www.nida-sasirangan.com. Berdasarkan penelusuran melalui internet, alamat tersebut sudah tidak ada lagi. Hal ini dapat dilihat dari pengecekan langsung ke 
alamat tersebut serta melalui situs www.whois.net dimana kedua domain tersebut sudah tidak ada yang memiliki atau tersedia buat dibeli. Hal ini berarti pemilik sebelumnya tidak memperpanjang lagi alamat domain tersebut sehingga menjadi alamat bebas yang dapat dimiliki oleh orang lain. Sehingga dapat disimpulkan bahwa website www.nida-sasirangan.co.id dan www.nida-sasirangan.com sudah tidak ada lagi.

Rozaq, dkk (2016) membuat website E-Commerce untuk Nida Sasirangan dengan model Business to Consumer (B2C). Model ini berarti pemilik website merupakan pihak yang berjualan. Model ini cocok untuk pedagang-pedagang besar tetapi kurang cocok untuk skala kecil atau UKM. Hal ini dikarenakan pada model B2C pedagang selain mengurusi barang dagangannya juga disibukan untuk mengurus keseluruhan proses transaksi online-nya sehingga memerlukan tenaga IT yang khusus untuk mengurusi website tersebut. Selain itu model ini kurang begitu dipercaya oleh calon pembeli atau konsumen karena transaksi keuangan dilakukan langsung tanpa pihak ketiga yang terpercaya. Saat ini trennya mengarah pada model Consumer to Consumer (C2C) atau marketplace.

Permasalahan Mitra dapat disimpulkan sebagai berikut:

1. Tidak adanya Nida sasirangan pada halaman pertama pencarian Google, baik itu pencarian website maupun pencarian lokal (local ranking).

2. Matinya website nida-sasirangan.co.id sehingga tidak bisa dilakukan optimasi search engine terhadap website tersebut.

3. Penjualan masih dilakukan secara offline melalui Toko tidak memanfaatkan marketplace.

\section{TARGET LUARAN}

Berdasarkan permasalahan yang telah dijelaskan pada bab sebelumnya, maka dapat dicari solusi dari permasalahan tersebut. Solusi yang dilakukan yaitu:

1. Pembuatan ulang website Nida Sasirangan yang menampilkan produk-produk dari Nida Sasirangan. Website tersebut dioptimasi dengan teknik-teknik SEO yang akan menaikkan peringkat pencarian website tersebut untuk kata kunci 'sasirangan'. Website tidak berupa e-commerce model B2C tetapi hanya menampilkan katalog produk, profil, lokasi toko offline serta tautan yang mengarah pada toko di marketplace. Hal ini dilakukan untuk mempermudah pengelolaan website sehingga tidak memerlukan tenaga IT profesional untuk mengurusnya.

2. Menaikkan peringkat lokal dari pencarian lokasi pada Google sehingga lokasi Nida Sasirangan yang saat ini berada pada posisi urut ke 17 dapat naik ke ranking yang lebih baik.

3. Memanfaatkan marketplace yang terkenal di Indonesia saat ini untuk sarana penjualan secara online sehingga akan memperluas jangkauan pasar tidak hanya di Banjarmasin tetapi juga ke daerah lain di Indonesia atau bahkan ke luar negeri.

Solusi-solusi tersebut diharapkan dapat meningkatkan penjualan produk sasirangan dari Nida Sasirangan. Ketika calon pembeli mencari pada mesin pencari dengan kata kunci 'sasirangan' diharapkan informasi produk-produk dari Nida Sasirangan berada pada halaman pertama pencarian sehingga semakin besar 
untuk dikunjungi. Semakin banyaknya pengunjung website, semakin memperbesar peluang meningkatnya penjualan. Adanya penjualan secara online melalui marketplace selain meningkatkan penjualan diharapkan juga akan memperluas jangkauan pasar dari Nida Sasirangan bahkan sampai ke luar negeri. Peningkatan penjualan sasirangan dari Nida Sasirangan diharapkan akan meningkatkan ekonomi masyarakat mitra kerja dari Nida Sasirangan.

Luaran yang ditargetkan yaitu berupa:

1) website yang menampilkan katalog produk serta berbagai informasi terkait penjualan produk-produk dari Nida Sasirangan yang telah diterapkan teknik SEO sehingga mendapatkan ranking pencarian yang baik pada mesin pencari (search engine). Website ini tidak memberikan layanan $e$ commerce $\mathrm{B} 2 \mathrm{C}$ tetapi hanya sarana untuk mempromosikan produk-produk dari Nida Sasirangan. Pada website akan diberikan tautan pembelian ke arah berbagai website e-commerce $\mathrm{C} 2 \mathrm{C}$ yang populer di Indonesia diantaranya Tokopedia, Bukalapak, Lazada, Shopee serta marketplace internasional yang memungkinkan.

2) Perbaikan local ranking Nida Sasirangan pada Google untuk kata kunci sasirangan.

3) Publikasi pada jurnal Pengabdian Masyarakat

\section{METODE PELAKSANAAN}

Pelaksanaan kegiatan Optimasi E-Commerce Dengan Penerapan Teknik SEO (Search Engine Optimization) untuk Meningkatkan Penjualan Pada UKM Nida Sasirangan digambarkan melalui Gambar 1.

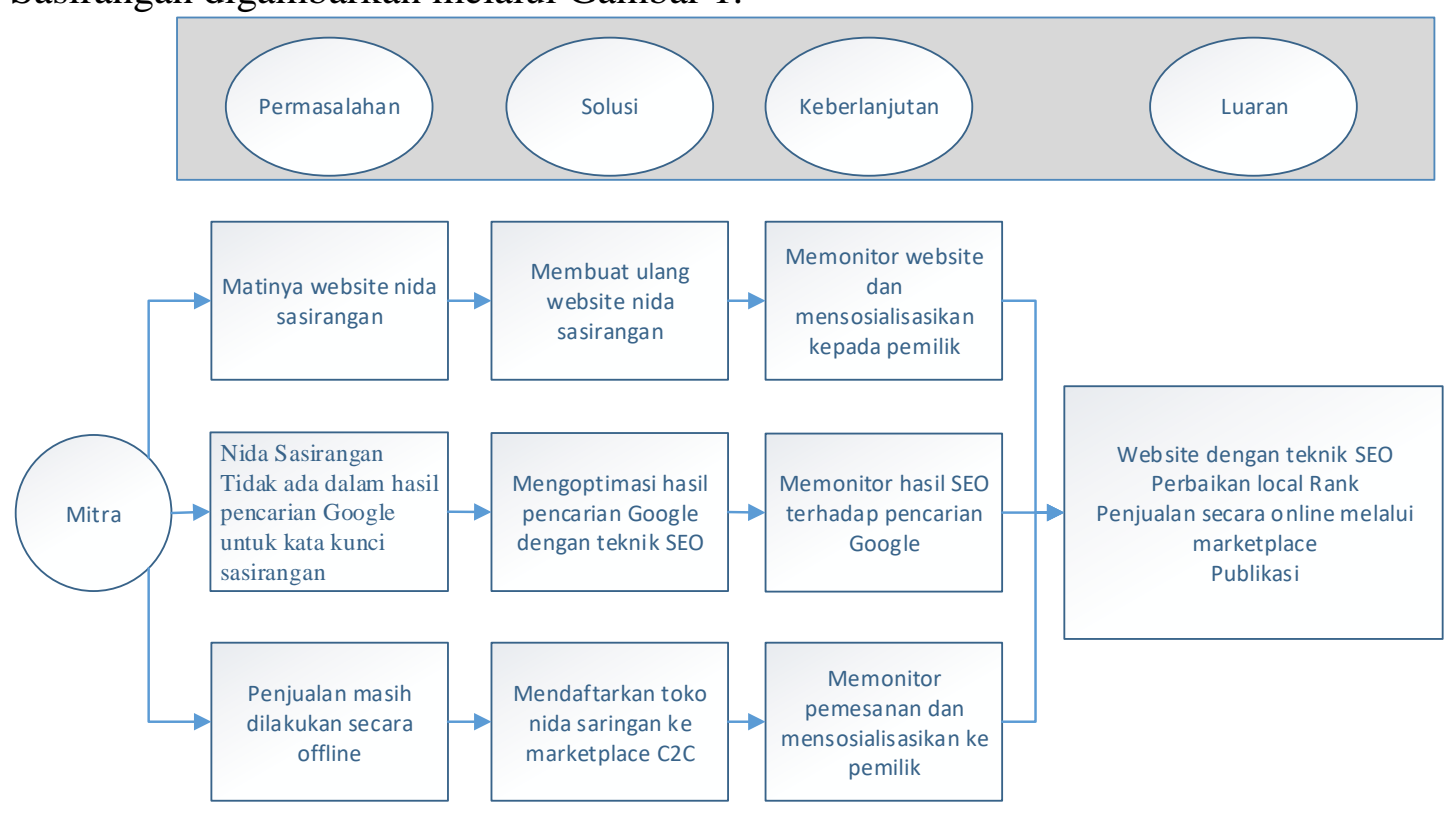

Gambar 1 Proses pelaksanaan kegiatan

Proses pembuatan website Nida Sasirangan menggunakan metode waterfall yang terlihat seperti Gambar 2. 


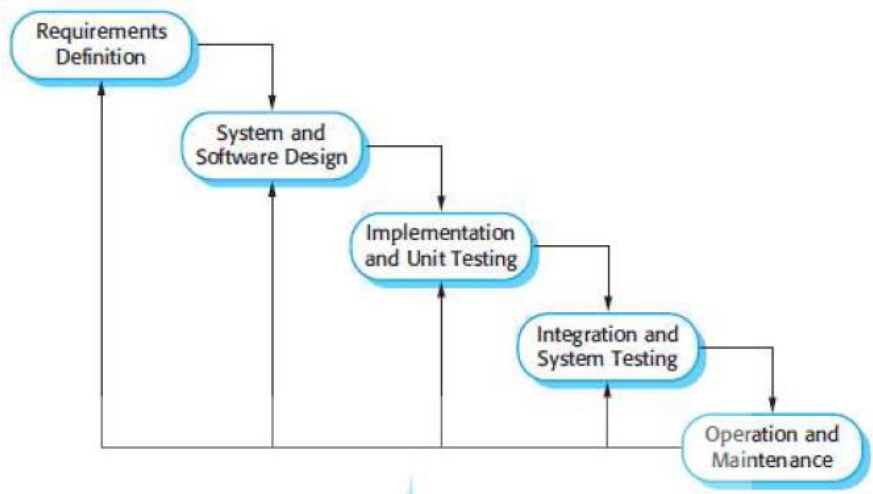

Gambar 2 Metode Waterfall (Sommerville, 2011)

Pada tahap Requirement Definition, diperlukan proses wawancara terhadap pemilik toko Nida Sasirangan agar sistem yang dibuat dapat sesuai dengan kebutuhan. Selain itu untuk pembuatan website dan pendaftaran hosting diperlukan berbagai data dari toko Nida Sasirangan seperti alamat lengkap, nomor telepon, alamat email hingga foto-foto produk. Data tersebut di dapat melalui wawancara serta berkunjung langsung ke toko Nida Sasirangan.

Setelah website dibuat selanjutnya dimasukkan konten yang sesuai dengan toko Nida Sasirangan. Konten dimasukkan dengan menerapkan teknik SEO agar mesin pencari memposisikan website pada halaman pertama. Untuk penjualan online, dibuat toko pada marketplace yang nantinya tautan toko tersebut diletakan pada halaman website sehingga memudahkan calon pelanggan untuk melakukan pembelian secara online. Pencarian local ranking juga dioptimasi untuk menaikan peringkat lokasi toko Nida Sasirangan.

Sistem yang telah dibuat kemudian dilakukan testing sekaligus juga dilakukan penyempurnaan. Testing juga melibatkan pemilik toko Nida Sasirangan agar mendapatkan feedback langsung untuk penyempurnaan sistem yang telah dibuat.

\section{HASIL DAN LUARAN YANG DICAPAI}

Pada pencarian lokasi Nida Sasirangan terdapat masalah yaitu seringnya Toko Nida Sasirangan berpindah alamat, sehingga pada pencarian lokasi terdapat lebih dari satu titik lokasi Nida Sasirangan sehingga menyebabkan pelanggan yang mencari alamat toko menjadi kesulitan. Untuk mengatasinya perlu melakukan usulan perubahan ke google.com terhadap titik-titik yang merupakan lokasi lama toko nida sasirangan. Setelah itu perlu dilakukan pengambilan satu titik untuk dijadikan pengakuan kepemilikan bisnis. Pada Gambar 3 menunjukkan titik pencarian nida sasirangan terdapat 2 titik, dimana sebelumnya terdapat 4 titik yang kemudian dihapus melalui usulan ke google.com. 


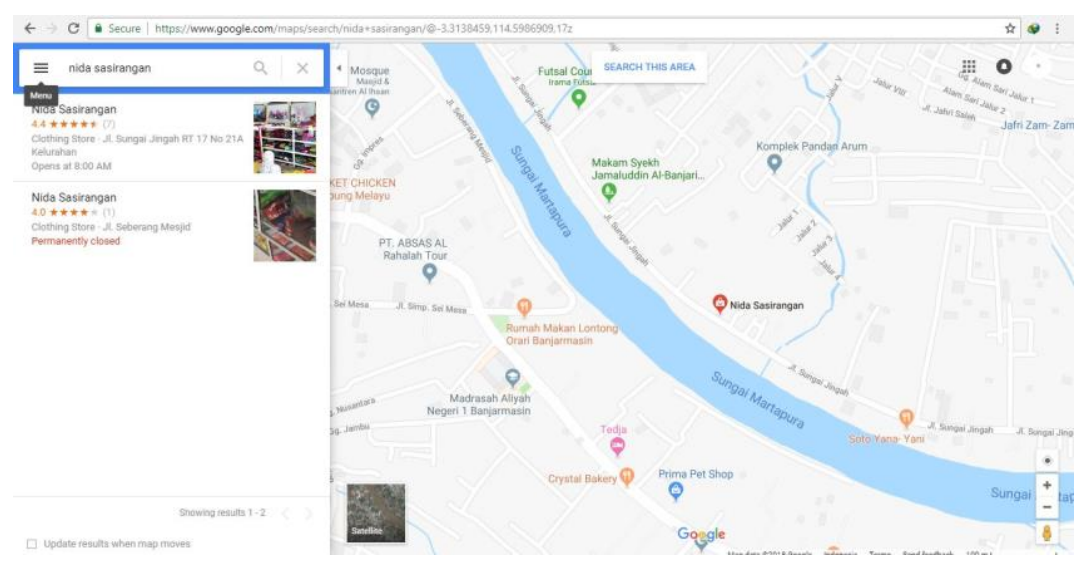

Gambar 3 Pencarian lokasi Nida Sasirangan

Untuk meningkatkan pencarian lokasi, google telah memberikan panduan dimana pemilik bisnis harus mengakui kepemilikan titik tersebut dengan mengklik "own this bussines?". Setelah berhasil dimiliki, selanjutnya perlu melengkapi data bisnis selengkap-lengkapnya dengan disertai foto-foto maupun video. Selain itu untuk meningkatkan ranking pencarian perlu secara rutin melakukan pembaharuan baik itu pembaharuan foto-foto, video maupun berinteraksi dengan merespon komentar-komentar dari pengguna internet.

Setelah dilakukan penghapusan titik serta pembaharuan data melalui google my business, hasil yang didapat dapat dilihat pada Gambar 4. Untuk pencarian dengan kata kunci "sasirangan Banjarmasin" posisi nida sasirangan sudah mengalami peningkatan seperti pada Gambar 5.

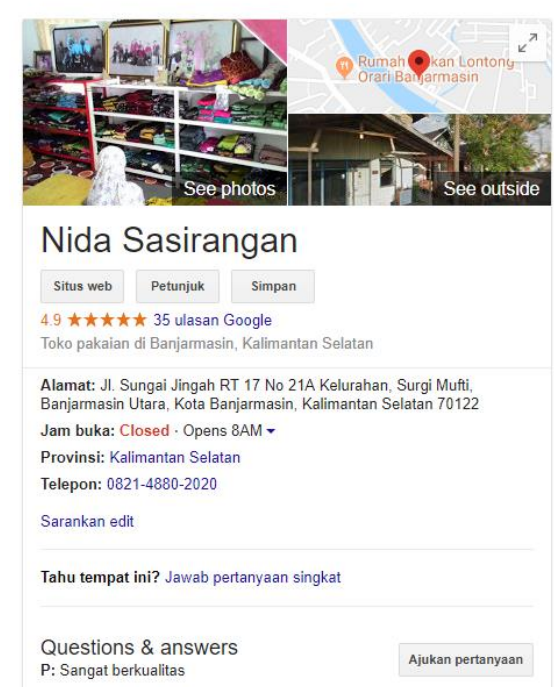

Gambar 4 Pencarian Lokasi Nida Sasirangan 


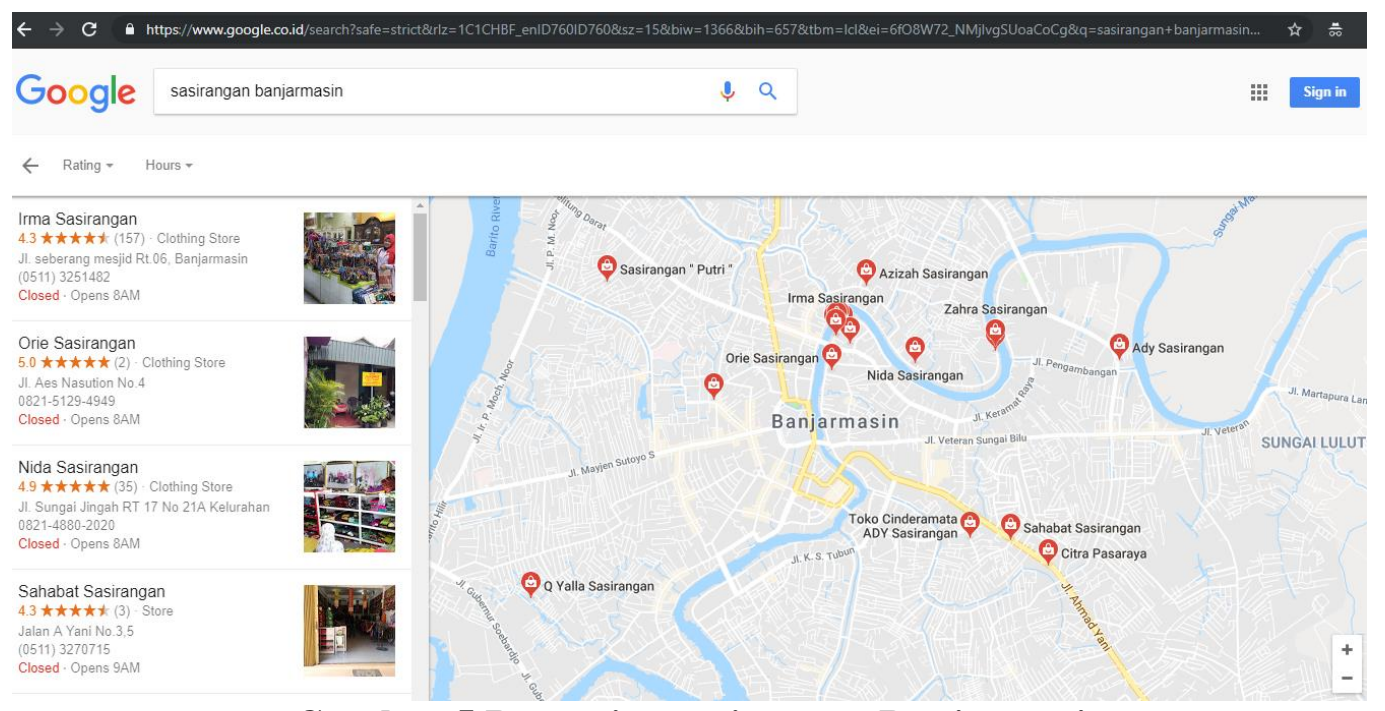

Gambar 5 Pencarian sasirangan Banjarmasin

\section{Pembuatan Akun pada Marketplace}

Salah satu cara untuk meningkatkan penjualan serta melakukan promosi yaitu dengan berjualan pada situs marketplace yang sudah cukup populer di Indonesia. Pada saat ini menggunakan situs Tokopedia sebagai tempat untuk berjualan, tetapi kedepan perlu dibuat toko pada berbagai marketplace lain yang populer di Indonesia.

Pada proses pembuatan akun ini terdapat masalah yaitu permalink nama toko nidasasirangan ternyata sudah dimiliki oleh orang lain pada marketplace Tokopedia sehingga terpaksa menggunakan nama toko dengan permalink nidasasiranganbj. Setelah dikonfirmasi ke pemilik toko, ternyata pernah dibuatkan akun pada marketplace, tetapi pemilik lupa alamat email yang digunakan. Untuk keberlanjutan kegiatan ini, dilakukan pelatihan kepada pemilik untuk melakukan pembaharuan barang pada tokopedia. Pada deskripsi akun tokopedia yang dibuat, disisipkan alamat website, social media, alamat, serta nomor ponsel dengan tujuan sebagai sarana promosi seperti yang terlihat pada Gambar $6 .$.

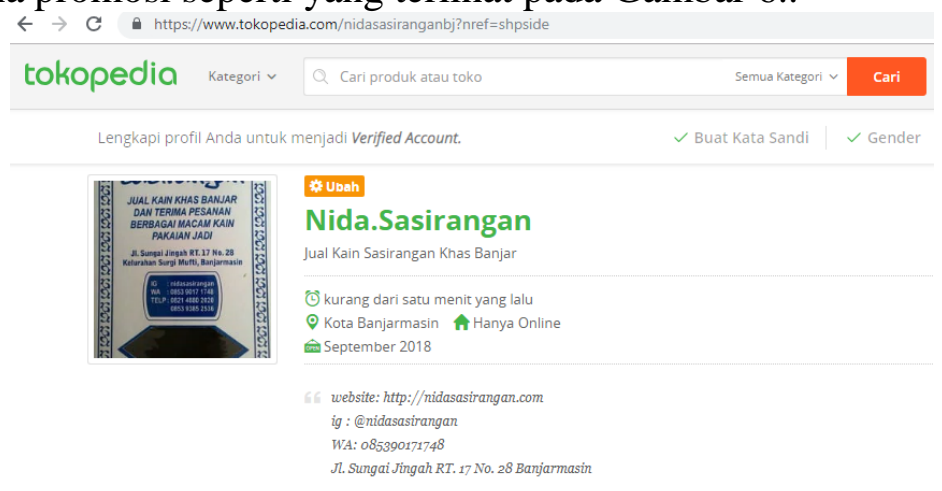

Gambar 6 Nida Sasirangan pada marketplace tokopedia.com 


\section{Pembuatan website nidasasirangan.com}

Untuk membuat website nidasasirangan.com diperlukan pembelian alamat domain serta hosting. Alamat domain dan hosting dibeli melalui layanan hostinger.co.id. Pada hostinger terdapat fasilitas pemasangan berbagai CMS yang dapat digunakan dalam pembuatan website. Sebagai pertimbangan kemudahan pengembangan dan banyaknya plugin yang tersedia, maka pembuatan website nidasasirangan.com menggunakan wordpress dengan plugin woocommerce. Tampilan website yang telah terpasang pada nidasasirangan.com terlihat pada Gambar 7.

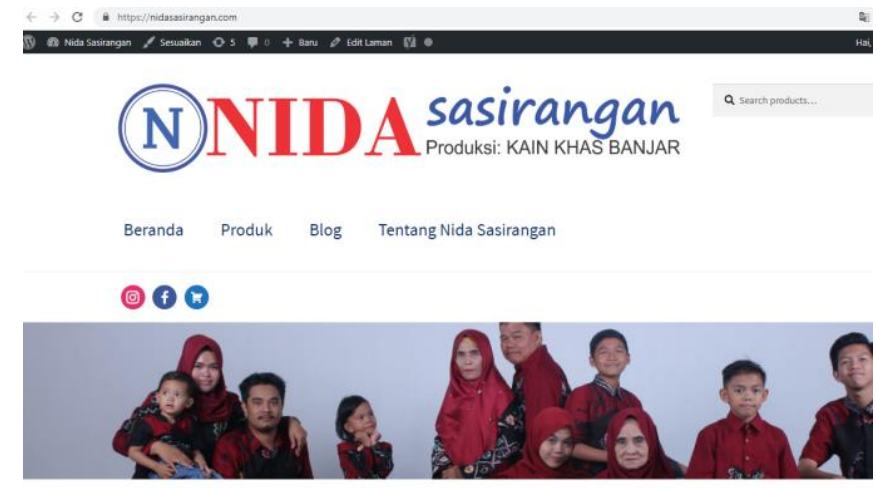

Gambar 7 Tampilan awal website

Setelah pemasangan wordpress, kemudian dilakukan pengisian konten. Konten web terbagi menjadi 4 halaman, yaitu halaman utama (Gambar 7), halaman produk (Gambar 8) yang berisi produk-produk yang dijual, halaman blog (Gambar 9) yang berisi tulisan dan informasi, serta halaman tentang nida sasirangan (Gambar 10) yang berisi sejarah serta alamat toko nida sasirangan.

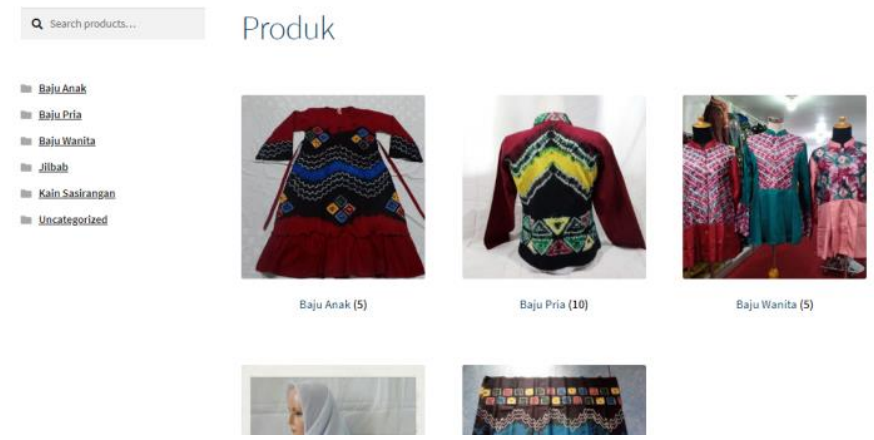

Gambar 8 Halaman produk 


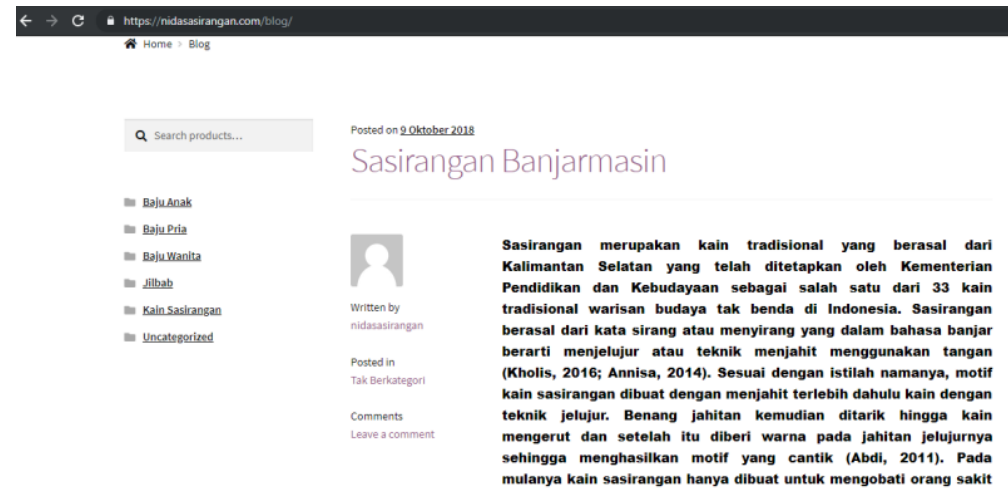

Gambar 9 Halaman Blog

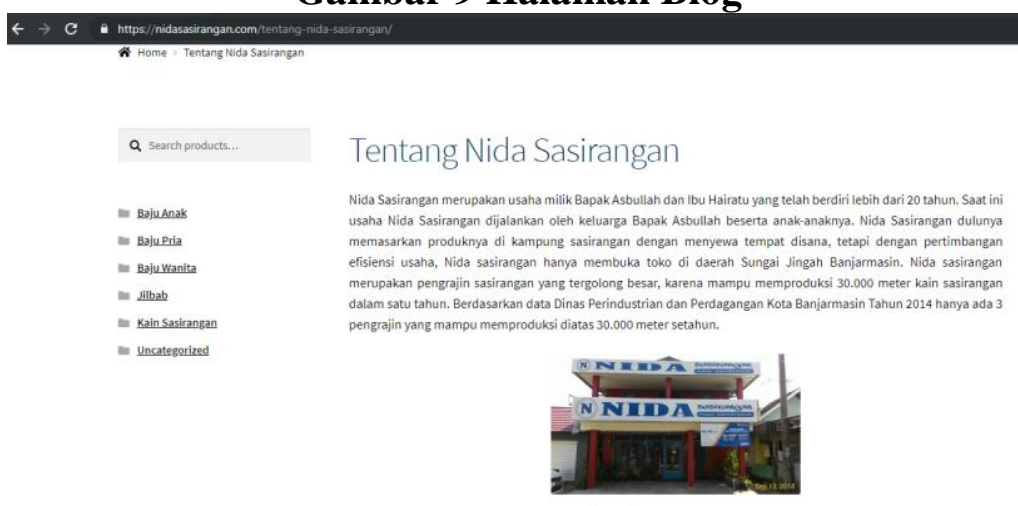

Gambar 10 Halaman Tentang Nida Sasirangan

Search Engine Optimization (SEO)

Setelah website dibuat, selanjutnya perlu dilakukan pengoptimalan SEO. untuk mempermudah pengoptimalan SEO yaitu dengan menggunakan plugin SEO by Yoast. Plugin ini akan memberikan saran serta langkah yang harus dilakukan untuk mengoptimalkan SEO.

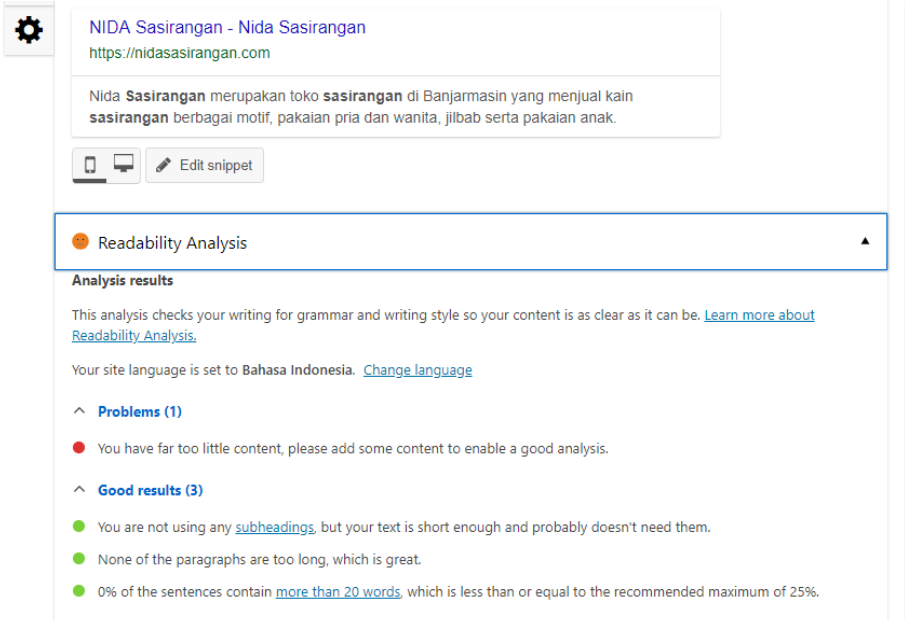

\section{Gambar 11 Menggunakan SEO by Yoast}

Dalam melakukan optimalisasi SEO, tahap pertama adalah riset kata kunci. Melalui riset kata kunci maka akan tahu kata kunci apa yang digunakan oleh pengguna Internet saat menggunakan mesin pencari. Salah satu website yang 
menyediakan layanan riset kata kunci adalah https://neilpatel.com/ubersuggest/. Hasil riset kata kunci "sasirangan” dapat dilihat pada Gambar 12.

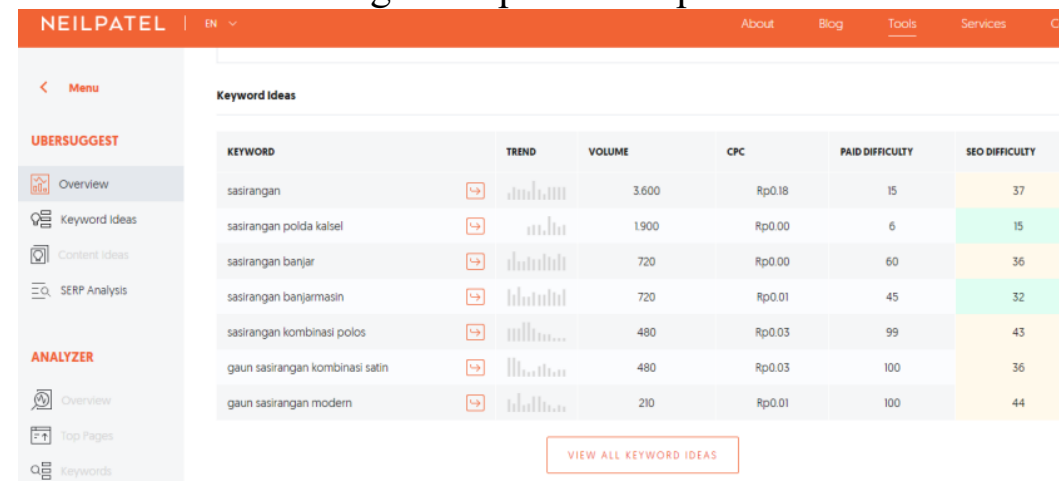

\section{Gambar 12 Hasil Riset Kata Kunci Sasirangan}

Untuk mempercepat pengindekan oleh mesin pencari google, perlu dimasukkan sitemaps dari website nidasasirangan.com ke google search console. Plugin SEO by yoast dapat digunakan untuk mendapatkan sitemap. Gambar 13 menunjukkan sitemap yang didapat dari plugin SEO by yoast.

\section{XML Sitemap}

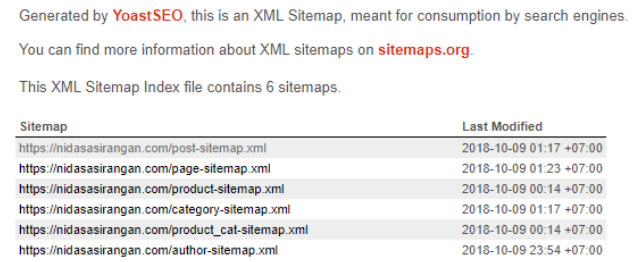

\section{Gambar 13 Sitemap website nidasasirangan.com}

Setelah mendapatkan sitemap, perlu dimasukkan pada google search console dimana sebelumnya perlu melakukan verifikasi website nidasasirangan dengan mendownload file .html dan kemudian menguploadnya ke hosting nidasasirangan.com.

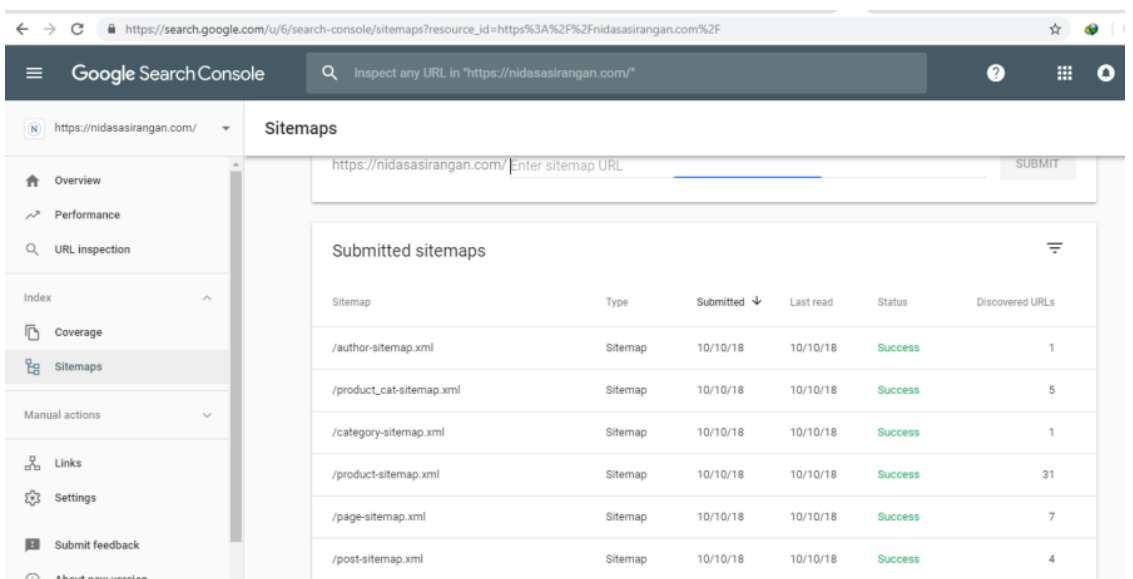

Gambar 14 Memasukkan sitemap ke google search console. 
Langkah berikutnya dalam optimasi SEO adalah dengan menambah konten dari website yang disertai dengan berbagai keyword hasil riset kata kunci. Kemudian juga dapat menambah backlink ke arah website nidasasirangan.com. Jika semua telah dilakukan maka tinggal menuggu google melakukan crawling dan indexing. Pada saat ini google belum melakukan proses re-crawling terhadap website nidasasirangan.com, sehingga konten website yang baru belum terlihat di google.

\section{KESIMPULAN}

Pencarian nida sasirangan pada mesin pencari google mendapat hasil yang jelek, hal ini disebabkan beberapa faktor diantaranya adalah website nidasasirangan.com yang sudah tidak aktif sehingga menyebabkan tidak terindeks mesin pencari lagi, lokasi toko nida sasirangan yang sering berpindah menyebabkan pengguna internet memberikan titik lokasi yang berbeda-beda sehingga membingungkan hasil pencarian lokasi, sedikitnya kata kunci nida sasirangan di internet sehingga mendapat hasil pencarian yang jelek.

Untuk meningkatkan hasil pencarian maka dilakukan beberapa langkah, diantaranya dengan membuat kembali website nidasasirangan.com dengan sekaligus mengoptimalkan kata kunci sasirangan dan nida sasirangan pada website tersebut. Solusi lainnya adalah dengan mengelola satu titik lokasi bisnis pada google dan mengusulkan agar dihapusnya titik lain yang sudah tidak relevan lagi dengan toko yang ada saat ini. Selain itu dengan melakukan update informasi lokasi bisnis tersebut dan secara rutin melakukan update foto juga dapat dilakukan agar ranking pencariannya semakin meningkat dan dengan memperbanyak kata kunci nida sasirangan di internet dengan membuat toko pada marketplace sebagai sarana promosi.

\section{DAFTAR PUSTAKA}

Abdi, M. 2011. Potensi Kain Sasirangan Peluang Bisnis Produk Kalimantan Selatan. Tugas Akhir. Sekolah Tinggi Manajemen Informatika dan Komputer STMIK Amikom Yogyakarta. Yogyakarta.

Aida, N. 2015. Peran Bank Indonesia Provinsi Kalimantan Selatan Terhadap Pengembangan dan Pemberdayaan Rumah Sasirangan di Kota Banjarmasin. Skripsi. Fakultas Syariah Dan Ekonomi Islam. UIN Antasari. Banjarmasin

Annisa, Y. 2014. Lebih Jauh Mengenal Batik Sasirangan. Bogor: Optima.

Badan Pusat Statistik Provinsi Kalimantan Selatan. 2009. PDRB Kabupaten/Kota Di Kalimantan Selatan Menurut Lapangan Usaha 2006-2008. Banjarmasin.

Ganie, T. N. 2014. Sasirangan Kain Khas Tanah Banjar. Kalimantan Selatan: Tuas Media

Kamal, A. 2015. Analisis Strategi Pengrajin Kain Sasirangan di Kampung Sasirangan, Banjarmasin (Studi Pada UKM Nida Sasirangan). Jurnal Ilmiah Mahasiswa FEB Universitas Brawijaya. Malang. 
Kholis, N. 2016. Kain Tradisional Sasirangan "Irma Sasirangan" Kampung Melayu Kalimantan Selatan. Skripsi. Program Studi Pendidikan Seni Rupa Fakultas Bahasa Dan Seni Universitas Negeri Yogyakarta. Yogyakarta.

Putra, M.R.A. 2011. Analisis Peranan Industri Kain Sasirangan Terhadap Perekonomian Kota Banjarmasin dan Strategi Pengembangannya (Periode 2005-2009). Skripsi. Departemen Ilmu Ekonomi Fakultas Ekonomi Dan Manajemen Institut Pertanian Bogor. Bogor.

Rozaq, A., dkk. 2016. Penerapan Model E-Commerce Guna Meningkatkan Daya Saing Usaha Kecil dan Menengah Produk Sasirangan Kota Banjarmasin. Jurnal Positif. Vol I. No 2 Hal:1-7.

Rozaq, A., dan Hardinto, R.K. 2016. Implementasi Sistem E-Commerce Guna Meningkatkan Daya Saing Usaha Kecil dan Menegah Produk Nida Sasirangan. Prosiding SNRT (Seminar Nasional Riset Terapan) 2016. Politeknik Negeri Banjarmasin.

Seman, S. 2007. Sasirangan Kain Khas Banjar. Kalimantan Selatan: Lembaga Pengkajian dan Pelestarian Budaya Banjar.

Sommerville, I. 2011. Software Engineering (Rekayasa Perangkat Lunak). Erlangga, Jakarta. 